\title{
PRINTO/PRES international website for families of children with rheumatic diseases: www.pediatric- rheumatology.printo.it
}

\author{
N Ruperto, P Garcia-Munitis, L Villa, M Pesce, A Aggarwal, A Fasth, T Avcin, S-C Bae, Z Balogh, \\ C Li, J De Inocencio, M Dibra, P Dolezalova, Y El Miedany, B Flato, M Harjacek, H-I Huppertz, \\ F Kanakoudi-Tsakalidou, N Wulffraat, P Lahdenne, J A Melo-Gomes, D Mihaylova, S Nielsen, \\ I Nikishina, H Ozdogan, K Pagava, V Panaviene, A-M Prieur, A-M Romicka, I Rumba, N Shafaie, \\ G Susic, S Takei, Y Uziel, R Vesely, P Woo, A Martini, for the Paediatric \\ Rheumatology International Trials Organisation (PRINTO) and the Paediatric \\ Rheumatology European Society (PRES)
}

Objective: To prepare a website for families and health professionals containing up to date information about paediatric rheumatic diseases (PRD).

Methods: Firstly, paediatric rheumatology centres and family self help associations were surveyed to characterise current clinical practice of physicians providing care for children with $P R D$, research activities, and training facilities of each centre. Secondly, international consensus was reached on the content of the website. Finally, the website was developed and the texts translated.

Results: The web page contains three main sections: (a) description for families of the characteristics of 15 PRD; (b) list of paediatric rheumatology centres; (c) contact information for family self help associations. A version for 45 countries in 52 languages (with another three in progress) is now available on the web. 291 surveys from 171 centres and 102 family associations were received from 42 countries. The median proportion of time spent in paediatric practice in the centres examined was $100 \%$, with $70 \%$ of this time dedicated to paediatric rheumatology. $90 \%$ of the centres were willing to perform clinical trials in the future.

Conclusions: The PRINTO/PRES website provides a well defined and competent set of information about PRD, with appropriate multiple translated versions and easy web navigational direction.

$\mathrm{P}$ aediatric rheumatic diseases (PRD) are rare conditions with substantial morbidity, with significant consequences for the quality of life of the child and his/her family, as well as the costs of health care and social care. The PRD comprise a group of heterogeneous chronic diseases, including juvenile idiopathic arthritis, juvenile systemic lupus erythematosus, juvenile dermatomyositis, juvenile scleroderma, and vasculitides.

Widespread availability of the internet allows families to access medical information quickly and easily, but this information is often not standardised, and is inaccurate and unreliable. Indeed, internet philosophy is that anyone can set up a website, but with the risk that, through ignorance or bias, the content of the site may not be correct even if the original information sources are reliable and accurate.
Ann Rheum Dis 2005;64:1101-1106. doi: 10.1136/ard.2004.030221

The European Commission, ${ }^{1}$ and the American Medical Association, ${ }^{2}$ have formulated guidelines for the development of websites containing medical information. The Paediatric Rheumatology International Trials Organization (PRINTO) ${ }^{3}$ in collaboration with the Paediatric Rheumatology European Society (PRES), supported by the European Union (contract 2001CVG4-808), has set up a project with the aim of preparing a website for families and health professionals. This website would contain consensus information about many of the PRD, a list of paediatric rheumatology centres, and a list of family self help associations. Moreover, in order to characterise the current clinical practice of physicians who provide care for children with PRD, research activities, and training facilities of each centre a survey was sent to paediatric rheumatology centres in 44 countries.

All information is available in the national language(s) of all the countries belonging to the PRINTO/PRES networks (www.pediatric-rheumatology.printo.it).

\section{METHODS}

\section{PRINTO and PRES networks}

PRINTO $^{3}$ is a non-profit international public network established in 1996 by 14 European countries (now including 44 countries and more than 180 centres world wide), which aims at fostering, facilitating, and coordinating the development, conduct, analysis, and reporting of studies to evaluate the efficacy and safety of drug treatments, quality of life, and outcome for children with PRD. PRINTO is composed of academic or clinical centres, or both, actively engaged in the research and clinical care of children with PRD.

PRES is an international scientific society for European healthcare professionals (and non-Europeans as associate members) working in the field of paediatric rheumatology. The mission of PRES is to promote knowledge of PRD, stimulate research in the field, disseminate knowledge through scientific meetings and publications, provide guidelines and standards for good clinical practice, for the training of doctors and allied health professionals in the practice of paediatric rheumatology.

Abbreviations: PRD, paediatric rheumatic diseases; PRES, Paediatric Rheumatology European Society; PRINTO, Paediatric Rheumatology International Trials Organization 


\section{Phases of the project \\ Phase 1}

The first phase comprised a survey of existing paediatric rheumatology centres and family self help associations in the countries that were members of PRINTO/PRES. Information was gathered through a questionnaire devised by PRINTO, and approved by PRES, sent to paediatric rheumatology centres in 44 countries, in order to characterise the current clinical practice of physicians who provide care for children with PRD, research activities, and training facilities of each centre. For the purpose of the survey a paediatric rheumatologist was defined as a physician whose workload consists of more than $50 \%$ paediatric rheumatology, or who is board certified in paediatric rheumatology, or who is recognised as one of the hospital/region/state acknowledged experts in paediatric rheumatology. Only the centres completing the survey were offered the opportunity to be listed on the website.

The survey was divided into sections in order to collect reliable information about:

- Section a: Demographics. Complete address of the centre with title, hospital, phone, fax, email, and website.

- Section b: Characteristics of the patient population of each centre. Time devoted to paediatric practice, total number of patients followed up, and new cases in the past year for all PRD; number of inpatients, outpatients, and paediatric rheumatology consultations for other departments in a typical week.

- Section c: Professional, teaching, and research activities. Time spent in patient care, teaching, clinical and/or laboratory research, administrative duties, etc; time spent in patients' care; presence of general paediatrics and/or paediatric rheumatology fellows and/or visiting fellows from other hospitals/countries; official recognition of paediatric rheumatology as a paediatric subspecialty.

- Section d: Clinical trials background. Number and type of paediatric and/or paediatric rheumatology clinical trials performed in the past 4 years and/or in progress; willingness to participate in future paediatric rheumatology clinical trials or reasons for inability to participate.

- Section e: Information on the centre. Type of hospital (children or general, or both; tertiary centre, affiliation to medical school); catchment area of the hospital with number of people; list of permanent staff dealing with paediatric rheumatology in the centre.

- Section f: Family help associations. Complete address of family self help association, phone, fax, email, and website.

- Section g: Curriculum vitae information. Age, English knowledge; year of graduation from medical school; specialties completed; years of experience in paediatric rheumatology, etc.

- Section h: Workforce information. Current workforce provision in each centre and information about planned future development of paediatric rheumatology in each country.

\section{Phase 2}

An international consensus conference was held on 1-2 March 2003 in Genoa (Italy), where 30 physicians dealing with PRD (the PRINTO national coordinators representing each of the countries in the network) gathered to reach consensus about the content of the web page, identification of rules and working groups for the preparation of documents to be released on the web, and identification of a referent physician for each centre participating in the project to whom the general public can address their request for information.
Each working group was assigned the task of preparing the master document on a specific PRD in the English language. The master documents for the PRD were then reviewed by all PRINTO national coordinators and, finally, the revised English version was translated into the languages of each country participating in the project.

\section{Phase 3}

The final phase, which was run in parallel with the previous two, was devoted to the development of the website. Two research coordinators with expertise in website development were specifically assigned to the preparation of the website and related database, while three other research assistants maintained contact with all the centres belonging to PRINTO/ PRES.

The website was developed with active server page technology (language visual basic script) directly connected to a Microsoft Access database located on the web server. The maps for all countries were developed as a "map system" using dynamic Macromedia Flash maps. In the "information" section (see below), all the documents are available both in html and Adobe PDF format.

\section{General methodology}

The project was conducted using well recognised consensus formation methodology specifically designed to combine judgments from a group of experts in a particular field: the Delphi Technique and Nominal Group Technique. ${ }^{45}$ The Delphi Technique uses a series of well defined questionnaire based surveys. The Nominal Group Technique is a structured face to face meeting designed to facilitate reaching consensus on the topic field of study. These techniques have been used extensively in the past. ${ }^{67}$ Consensus formation methodology must be designed so that each step is based on the results of the previous steps.

\section{RESULTS}

\section{Content of the website}

Forty five countries (52 languages) have been completed and are already on line (fig 1). The translation was original (from the consensus English version to the language of the country) for the following 29 countries (31 languages): Bulgaria, China, Croatia, Czech Republic, Denmark, Egypt, Finland, France, Georgia, Germany, Greece, Hungary, India, Israel, Italy, Japan, Latvia, Lithuania, Netherlands, Norway, Poland, Portugal, Russia, Serbia Montenegro, Slovakia, Slovenia, South Korea, Spain (Castilian, Catalan, and Galician), Turkey, United Kingdom.

The translation was adapted from the original languages for the following 15 countries (20 languages): Argentina, Australia, Austria, Belgium (Flemish and French), Brasil, Chile, Costa Rica, Cuba, Ireland, Luxembourg (French, German), Mexico, Singapore (English and Chinese), Saudi Arabia, Switzerland (French, German and Italian), Tunisia.

For a further three countries translation is in progress: Albania, Iran, Sweden.

The flags of all countries participating in the project with the names of each state translated into appropriate languages are listed on the home page of the website (http:// www.pediatric-rheumatology.printo.it). Because this page has to be accessed by people with different languages the initial connection was visually prepared making it as simple as possible to facilitate navigation.

The click on a flag links to the section specific to that country. For each country there is a translated introductory statement and three specific sections. The general structure is the same for all countries. 


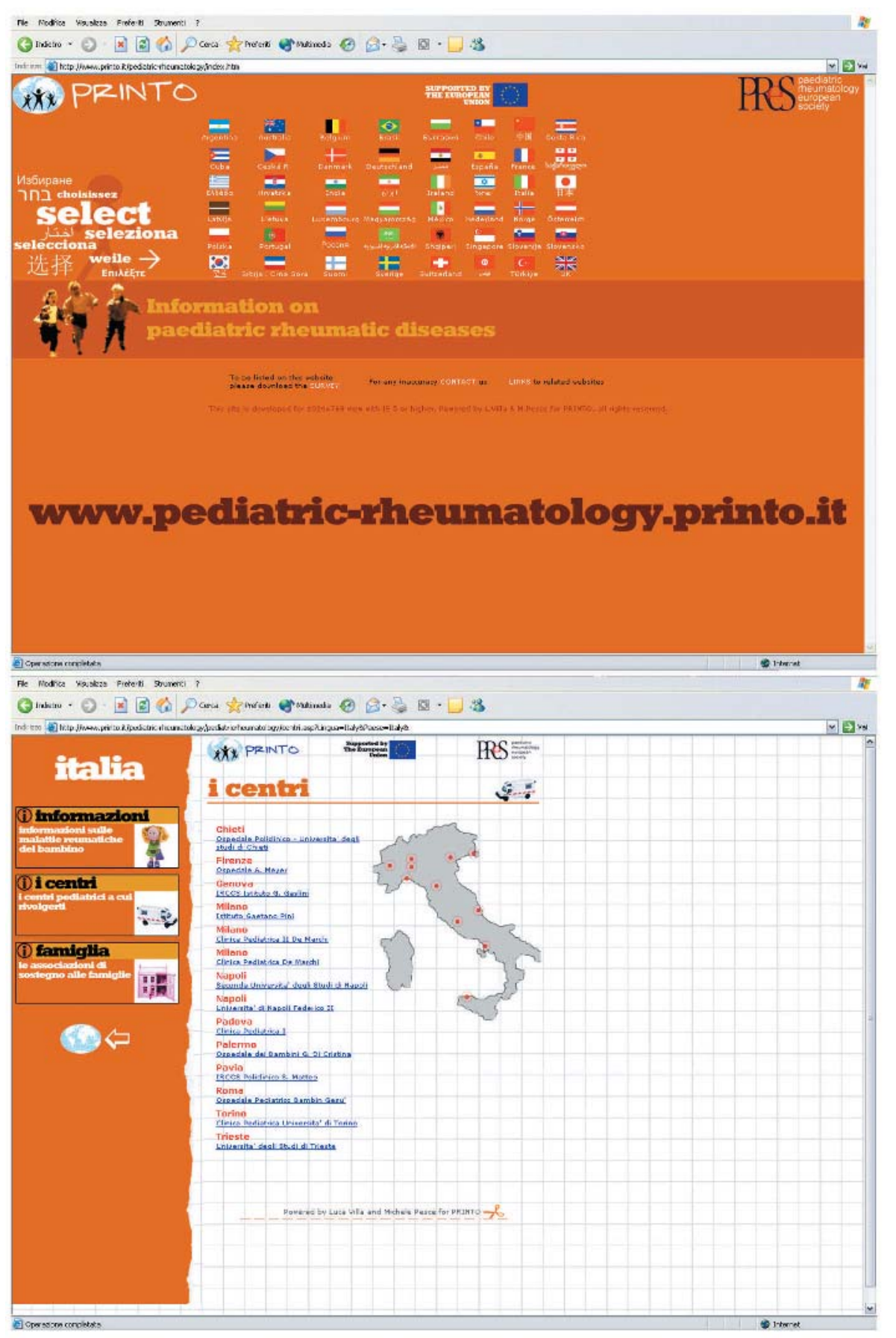

Figure 1 Home page of the website and home page specific for Italy with terms in Italian. The structure of the home page for each country is the same as for Italy with all the terms translated into the language of the specific country.

First section

The first section aims at giving families an up to date description of the characteristics of the listed PRD. Each text is written in the frequently asked questions format (What is it? How frequent is it? etc).

Specific text can be found for the following diseases: juvenile idiopathic arthritis, juvenile systemic lupus erythematosus (including antiphospholipid antibodies, and neonatal lupus), juvenile dermatomyositis, juvenile scleroderma, juvenile spondyloarthropathies, Kawasaki's disease, HenochSchönlein purpura, primary systemic vasculitis (polyarteritis nodosa, Takayasu's arteritis, Wegener's granulomatosis, other vasculitides), rheumatic fever and post-streptococcal reactive arthritis, Behçet's disease, Lyme arthritis, pain syndromes (fibromyalgia syndrome, growing pains, benign hypermobility syndrome, etc), recurrent fevers related to a genetic anomaly (tumour necrosis factor receptor associated periodic syndrome, mevalonate kinase associated periodic fever syndrome, or hyper-IgD syndrome, etc), familial Mediterranean fever, drug treatment (non-steroidal antiinflammatory drugs, ciclosporin, intravenous immunoglobulins, corticosteroids, azathioprine, cyclophosphamide, methotrexate, hydroxychloroquine, sulfasalazine, colchicine, anti-tumour necrosis factor agents).

\section{Second section}

The second section lists the paediatric rheumatology centres existing in that country. Information about a specific centre can be accessed via the list of centres or visually via the map of the country where all the centres are depicted. For each 
Table 1 Proportion of time spent by professional, teaching, and research activities

\begin{tabular}{|c|c|}
\hline & $\begin{array}{l}\text { Time spent (median; min-max) } \\
(\mathrm{n}=164)\end{array}$ \\
\hline \multicolumn{2}{|l|}{ Patient care: } \\
\hline Paediatric rheumatology & $70(2-100)$ \\
\hline General paediatric & $30(0-93)$ \\
\hline Adult rheumatology & $10(0-90)$ \\
\hline Teaching & $10(0-70)$ \\
\hline Clinical research & $10(0-85)$ \\
\hline Laboratory research & $0(0-40)$ \\
\hline Administrative duties & $10(0-65)$ \\
\hline
\end{tabular}

centre the name of the responsible physician and the permanent staff with colour photos, complete address, telephone, fax, email, and hospital website are provided. Families can reach physicians by email with a direct link and can also get specific information on the hospital through the direct link to its website. The steering committee of the project decided to put on the web only the contact information (address) to avoid any judgment about the quality of the centre. This list will be updated regularly and does not pretend to be exhaustive.

\section{Third section}

The third section gives the contact information for the family help associations (charities or similar) that can be found in the different countries, with a link to their email and website.

\section{Web questionnaire survey \\ Section a: Demographics}

The survey was sent to 229 centres, members of PRINTO and/ or PRES. A total of 291 surveys were received from 42 different countries, with some centres sending more than one survey. To avoid redundancy in the results, for the purposes of the analysis we considered only the survey completed by the centre director for a total of 171/229 (75\%).

All the values reported in the following sections are medians if not otherwise specified.

\section{Section b: Characteristics of the patient population of each centre}

Because some paediatric patients are seen in a hospital for adults we wanted to check the proportion of paediatric practice in the centres examined and found that it was equal to $100 \%$, with only 10 centres $(6 \%)$ dealing with less than $50 \%$ of paediatric patients. Juvenile idiopathic arthritis was the most frequent PRD seen, followed by juvenile systemic lupus erythematosus.

In a typical week (taking the median value) within a centre, 2 inpatient, 28 outpatient, and 4 paediatric rheumatology consultations were conducted for other departments.

\section{Section c: Professional, teaching, and research activities}

Table 1 reports the median time spent for professional, teaching, and research activities. Most of the time (58\%) is dedicated to patient care, with $70 \%$ of this time dedicated to paediatric rheumatology patients. The time dedicated to laboratory research is limited and with a wide range of variation from centre to centre, while distribution of efforts was similar for other responsibilities, such as teaching, clinical research, and administrative duties.

\section{Section d: Clinical trials background}

A total of $131 / 158(83 \%)$ centres had participated in at least one paediatric clinical trial in the past 4 years (median three paediatric trials, of which two where paediatric rheumatology trials).

A total of $154 / 171(90 \%)$ centres were willing to perform future investigator initiated clinical trials, while a smaller number of centres 138/171 (81\%) were willing to participate in pharmaceutical company sponsored clinical trials, which usually require more time.

For the centres that did not want to participate in future paediatric rheumatology clinical trials the two main reasons listed were that they do not have time to participate and/or that they do not sufficient manpower and support.

\section{Section e: Information on the centre}

A hospital website was available in 121 (71\%) centres; this information might be an underestimate because it is based mainly on information provided by the centres.

A total of 68/154 (44\%) centres were paediatric hospitals only, 53 (34\%) were general hospitals, and $33(21 \%)$ both. There are 146/154 (95\%) tertiary care centres and 141 of the $154(92 \%)$ centres are affiliated to a medical school, with 123/ $154(80 \%)$ centres located in an area with at least 500000 inhabitants.

\section{Section f: Family help association}

The survey identified 103/164 (63\%) family help associations (charities or similar); of these, $51(50 \%)$ provided a website.

\section{Section g: Curriculum vitae information}

For this section the analysis was performed for all surveys received.

Fifty five per cent $(89 / 162)$ of units that responded to the survey were directed by female physicians. Their median age was 48 years (32-64). Of the 261 physicians who responded to the survey, $150 / 242(62 \%)$ were women, with a median age of 48 years.

Physicians had a median of 24 years (range 7-55) of medical experience, with a median of 13 years $(0.3-37)$ of specific experience in paediatric rheumatology.

For non-English speaking countries, knowledge of English was characterised as basic in $47(21 \%)$, good in $94(41 \%)$, and fluent in $88(38 \%)$ respondents.

\section{Section i: Workforce information}

The great majority of the paediatric rheumatologists in the survey 82/132 (62\%) did not consider that other specialists were competing to take over the care of children with PRD over the past 2 years.

There is a need to increase the number of paediatric rheumatologists in the area/region around each hospital for $86 / 145(59 \%)$ respondents, and the need is even greater in each country for $105 / 146(72 \%)$ but, despite this necessity, $84 / 146(58 \%)$ think that no other paediatric rheumatologist will be employed, in the next 5 years. The paediatric rheumatology practice in each area is expanding for 124/ $148(84 \%)$, but the job opportunities in the near future will stay the same for $80 / 144(56 \%)$.

Despite the perceived manpower shortages the morale for the great majority $(107 / 142(75 \%))$ of paediatric rheumatology centres is good/excellent.

\section{DISCUSSION}

Families can now access the internet for health information with greater ease, but the quality of the available information is not always good. To provide good quality information for the families of children with PRD, PRINTO and PRES undertook this project to develop a consensus derived website 
responding to published guidelines, ${ }^{128}$ which can be regarded as a model for future development of a website containing standardised and up to date medical information directed to families and health professionals.

The website has just been completed and, so far, its promotion among potential users is only at the initial stage. It is expected that once specific links to our website are developed in well established national sites, the number of connections will increase. Despite this initial limitation, a consistent number of hits have already taken place. In March 2004 about 3000 people a month visited the site, with more than 13000 specific pages accessed from 64 countries. This number increased to 9000 visitors a month from 85 countries in June. At the end of February when we started to advertise the website among all the physicians and family help associations in the PRINTO/PRES mailing list (about 800 contacts), access increased from the first to the second week of March by $166 \%$.

Many users came from small countries who wrote "keywords" in their own national language instead of English. Our website greatly facilitates the access for families to medical information translated into their own language. Access to physicians and hospitals is sometimes difficult owing to time constraints and heavy work schedules, and the possibility of reaching the hospital by email will surely facilitate family-doctor relations.

It is a recognised limitation of the texts on PRD provided by this website, that in this first phase they were prepared just by physicians, with limited input from family associations or allied health professionals. Future revisions of the available brochures will have to take into account comments coming directly from families.

Over the past 30 years, paediatric rheumatology has evolved from a small group of internists and paediatricians interested in childhood rheumatic diseases to a board certified subspecialty, at least in some countries, and is established as a subsection of paediatrics within the Union of European Medical Specialists (UEMS), which reports to the EU commission.

Most of the centres surveyed were located in tertiary hospitals in highly populated areas. As observed in general paediatrics most of the practising physicians are female $(62 \%)$, while $55 \%$ of physicians in charge of their units are women also.

The clinical practice load was high with little time left for research. Despite this limitation, $80 \%$ of the centres examined had participated in at least one clinical trial during the past 4 years. This high level of participation may be due to two main factors. Firstly, we surveyed members of PRINTO, a big international network with the specific aim of carrying out collaborative clinical research, and so there is a built-in bias. PRINTO has connections all over the world, including areas, like Latin America, which were previously not included in international studies. Secondly, the paediatric rule issued by the Food and Drug Administration (FDA) ${ }^{10}$ that now requires manufacturers of products likely to be used in children to study those products in the relevant paediatric population. Similar rules are currently discussed also by the European Medical Evaluation Agency (EMEA). ${ }^{11}{ }^{12}$

From the survey, it is quite clear that future development in the field should deal with national regulations facilitating the establishment of paediatric rheumatology centres in a less well served area and establishing the minimum and maximum numbers of specialists needed.

In conclusion, visitors to the PRINTO/PRES website are given a well defined and competent set of information about PRD, with appropriate multiple translated versions and easy web navigational directions. A by-product is important practice information from the survey of clinical centres and clinical practice in the participating countries.

\section{ACKNOWLEDGEMENTS}

We are indebted to Drs Monica Tufillo, Elisabetta Maggi, and Anna Tortorelli for their help in data handling, organisational skills, and overall management of the project.

Supported by the Directorate of Public Health of the European Union (contract No 2001CVG4-808) and by IRCCS G Gaslini of the University of Genoa, Genoa, Italy.

\section{Authors' affiliations}

N Ruperto, P Garcia-Munitis, L Villa, M Pesce, A Martini, IRCCS G. Gaslini, Pediatria II Reumatologia, PRINTO, Genova, Italy

A Aggarwal, Sanjay Gandhi Institute of Medical Sciences, Lucknow, India

A Fasth, The Queen Silvia Children's Hospital, Göteborg, Sweden

T Avcin, University Medical Centre Ljubljana, Ljubljana, Slovenia

S-C Bae, The Hospital for Rheumatic Diseases, Hanyang University

Medical Centre, Seoul, South Korea

Z Balogh, National Institute of Rheumatology and Physiotherapy,

Budapest, Hungary

C Li, Beijing Children's Hospital, Capital, Beijing, China

J De Inocencio, CS Estrecho de Corea, Madrid, Spain

M Dibra, University Hospital Centre Mother Terza, Tirana, Albania

P Dolezalova, 1 st Faculty of Medicine and General Faculty Hospital,

Prague, Czech Republic

Y E Miedany, Ain Shams University, Cairo, Egypt

B Flato, Rikshospitalet University Hospital, Oslo, Norway

M Harjacek, Children's Hospital Zagreb, Zagreb, Croatia

H-I Huppertz, Zentralkrankenhaus, Bremen, Germany

F Kanakoudi-Tsakalidou, Aristotle University of Thessaloniki -

Ippokration General Hospital, Thessaloniki, Greece

N Wulffraat, Wilhelmina Kinderziekenhuis, Utrecht, Netherlands

P Lahdenne, Hospital for Children and Adolescents, Helsinki University

Central Hospital, Helsinki, Finland

J A Melo-Gomes, Instituto Portugues de Reumatologia, Lisbon, Portugal

D Mihaylova, University Children Hospital, Sofia, Bulgaria

S Nielsen, Juliane Marie Centret, Rigshospitalet, København, Denmark

I Nikishina, Institute of Rheumatology RAMS, Moscow, Russia

H Ozdogan, Cerrahpasa Tip Fakültesi, Istanbul, Turkey

K Pagava, Tbilisi State Medical University, Tbilisi, Georgia

V Panaviene, Vilnius University, Vilnius, Lithuania

A-M Prieur, Hôpital Necker Enfants Malades, Paris, France

A-M Romicka, Institute of Rheumatology, Warsaw, Poland

I Rumba, University of Latvia, Riga, Latvia

N Shafaie, Iran University of Medical Sciences, Teheran, Iran

G Susic, Institute of Rheumatology, Belgrade, Belgrade, Serbia

Montenegro

S Takei, Faculty of Medicine, Kagoshima University, Kagoshima city,

Japan

Y Uziel, Meir Medical Centre, Kfar Saba, Israel

R Vesely, University Hospital, Kosice, Slovakia

P Woo, Great Ormond Street Children Hospital, London, UK

A Martini, Università di Genova, Genova, Italy

Additional PRINTO national coordinators who adapted the original translation to the language of their country: Sulaiman Al-Mayouf, MD (Riyadh, Saudi Arabia), Boel Andersson-Gare (Jonkoping, Sweden), Rym Hajir Ben Ammar, MD (El Menzah, Tunisia), Ruben Burgos-Vargas, MD (Mexico City, Mexico), Cecilia Coto Hermosilla, MD (Habana, Cuba), Carmen de Cunto, MD (Buenos Aires, Argentina), Stella Maris Garay, MD (La Plata, Argentina), Michaël Hofer, MD (Lausanne, Switzerland), Christian Huemer, MD, Prof (Bregenz, Austria), Rik Joos, MD (Gent, Belgium), Anton Jordi, MD (Barcelona, Spain), Claudia Machado, MD (Botucatu, Brasil), Marta Miranda, MD (Providencia Santiago de Chile, Chile), Kevin Murray, MB.BS., FRACP (Perth, WA, Australia), Oscar Porras, MD, PhD Chief Immunology (San Jose, Costa Rica), Madeleine Rooney, MD, MRCP (Belfast, Ireland), Yvonne See, MD (Singapore, Singapore), Charles Spencer (Chicago, IL, USA).

All authors declare that they (a) provided a substantial contribution to the conception and design, or acquisition of data, or analysis and interpretation of data; (b) participated in the drafting the article or revising it critically for important intellectual content; (c) approved the final version to be published; (d) have no relevant financial interest in the manuscript. 
Written permission was obtained from all people named in the "Acknowledgements".

Correspondence to: Dr N Ruperto, Paediatric Rheumatology INternational Trials Organisation (PRINTO), IRCCS G. Gaslini, Pediatria II Reumatologia, Largo Gaslini, 5, 16147 Genova, Italy; nicolaruperto@ ospedale-gaslini.ge.it

Accepted 15 December 2004

Published Online First 10 March 2003

\section{REFERENCES}

1 Commission of the European Communities, Brussels, Belgium. eEurope 2002: quality criteria for health related websites. J Med Internet Res 2002;4:e15.

2 Winker MA, Flanagin A, Chi-Lum B, White J, Andrews K, Kennett RL, et al. Guidelines for medical and health information sites on the internet - principles governing AMA web sites. JAMA 2000;283:1600-6.

3 Ruperto N, Martini A. International research networks in pediatric rheumatology: the PRINTO perspective. Curr Opin Rheumatol 2004: 16:566-70

4 Delbecq AL, Van de Ven AH, Gustafson DH. Group Techniques for program planning. A guide to nominal group and Delphi processes, 1 st ed. Glenview, III. : Scott, Foresman and Company, 1975.
5 Sniderman AD. Clinical trials, consensus conferences, and clinical practice. Lancet 1999;354:327-30

6 Giannini EH, Ruperto N, Ravelli A, Lovell DJ, Felson DT, Martini A. Preliminary definition of improvement in juvenile arthritis. Arthritis Rheum 1997;40:1202-9

7 Ruperto N, Ravelli A, Murray KJ, Lovell DJ, Andersson-Gare B, Feldman BM, et al. Preliminary core sets of measures for disease activity and damage assessment in juvenile systemic lupus erythematosus and juvenile dermatomyositis. Rheumatology (Oxford) 2003;42:1452-9.

8 Prady SL, Norris D, Lester JE, Hoch DB. Expanding the guideline for electronic communication with patients. Application to a specific tool. J Am Med Inform Assoc $2001 ; 8: 344-8$

9 Connor JD. A look at the future of pediatric therapeutics: an investigator's perspective of the new pediatric rule. Pediatrics 1999;104:610-13.

10 FDA. Regulations requiring manufacturers to assess the safety and effectiveness of new drugs and biologic products in pediatrics patients (21 CFR Parts 201, 312, 314, and 601). Federal Register 1998:63.

11 Ruperto N, Martini A, for the Paediatric Rheumatology International Trials Organization (PRINTO). Use of unlabelled and off licence drugs in children. A European paediatric rule is needed to protect children. BMJ 2000;320:1210-11

12 European Commission. Proposal for a regulation of the European Parliament and of the Council on medicinal products for paediatric use and amending Regulation (EEC). No 1768/92, Directive 2001/83/EC and Regulation (EC) No $726 / 2004$. Available at http://pharmacos.eudra.org/F2/Paediatrics/ docs/_2004_09/EN.pdf (accessed 8 April 2005). 